\title{
Nanostructured systems containing babassu (Orbignya speciosa) oil as a potential alternative therapy for benign prostatic hyperplasia
}

This article was published in the following Dove Press journal:

International Journal of Nanomedicine

17 August 2013

Number of times this article has been viewed

\author{
Valeria Pereira de Sousa' \\ Joanne Crean ${ }^{2}$ \\ Vinícius Raphael de \\ Almeida Borges' \\ Carlos Rangel Rodrigues' \\ Lidia Tajber ${ }^{2}$ \\ Fabio Boylan ${ }^{2}$ \\ Lucio Mendes Cabral' \\ 'Department of Pharmaceutics, \\ Faculty of Pharmacy, Federal \\ University of Rio de Janeiro, Rio de \\ Janeiro, Brazil; ${ }^{2}$ School of Pharmacy \\ and Pharmaceutical Sciences and \\ Trinity Biomedical Sciences Institute, \\ Trinity College Dublin, Dublin, Ireland
}

Correspondence: Valeria Pereira de Sousa

Department of Pharmaceutics, Faculty of Pharmacy, Federal University of Rio de Janeiro CCS, BI Bss, Sala 15, Ilha do Fundão, 21 941 -590, Rio de Janeiro, Brazil

Tel +55 2l 25647380

Fax +55 2I 25647380

Email valeria@pharma.ufrj.br

\begin{abstract}
The oil of babassu tree nuts (Orbignya speciosa) is a potential alternative for treatment and prophylaxis of benign prostatic hyperplasia. Improved results can be obtained by drug vectorization to the hyperplastic tissue. The main objective of this work was the preparation and characterization of poly(lactic-co-glycolic acid) (PLGA) nanoparticle and clay nanosystems containing babassu oil (BBS). BBS was extracted from the kernels of babassu tree nuts and characterized by gas chromatography-mass spectrometry as well as ${ }^{1} \mathrm{H}$ and ${ }^{13} \mathrm{C}$ nuclear magnetic resonance. BBS-clay nanosystems were obtained by adding polyvinylpyrrolidone, Viscogel B8 ${ }^{\circledR}$, and BBS at a 2:1:1 mass ratio and characterized by X-ray diffraction, thermogravimetric analysis, infrared spectroscopy, and laser diffraction. The PLGA-BBS nanoparticles were prepared by the precipitation-solvent evaporation method. Mean diameter, polydispersity, zeta potential, and scanning electron microscopic images of the nanosystems were analyzed. Thermogravimetric analysis showed successful formation of the nanocomposite. PLGA nanoparticles containing BBS were obtained, with a suitable size that was confirmed by scanning electron microscopy. Both nanostructured systems showed active incorporation yields exceeding $90 \%$. The two systems obtained represent a new and potentially efficient therapy for benign prostatic hyperplasia.
\end{abstract}

Keywords: babassu oil, nanocomposite, poly(lactic-co-glycolic acid), nanoparticles, benign prostatic hyperplasia, treatment, nanotechnology

\section{Introduction}

Benign prostatic hyperplasia (BPH) is a common condition in men over 40 years of age, and $68 \%$ of men older than 50 years have symptoms associated with the disease. ${ }^{1} \mathrm{BPH}$ is characterized by a prostate volume increase that is due to stromal and epithelial cell hyperplasia interfering with urinary flow. This in turn causes polyuria, urinary retention, nocturia, urinary hesitancy, and an increased risk of urinary tract infection. ${ }^{2}$ Treatment for BPH is based on inhibition of testosterone synthesis by finasteride and its analogs in association with adrenergic blocking drugs, such as doxazosin and tamsulosin. ${ }^{3}$ As an alternative to drug therapy, surgical removal of the prostate is a more radical option that presents many problems for the patient during the postoperative period. ${ }^{4}$ Plant oils have been suggested as an alternative and less aggressive option to synthetic drugs for $\mathrm{BPH}^{5,6}$ and it has been proposed that they can also be used in BPH prophylaxis. Saw palmetto oil is a promising candidate for this application. ${ }^{7-9}$ Among the various palm extracts used to control BPH, the oil of the babassu tree nut (Orbignya speciosa, Arecaceae family), which is found primarily in the northern and northeastern parts of Brazil, has considerable potential. ${ }^{10}$ Other parts of this fruit are known for their analgesic and anti-inflammatory properties, and immunomodulatory activity has also been 
described for other babassu extracts. ${ }^{11}$ Babassu extracts have also been described in the treatment of leukemia and benign and malignant hypertrophy of the prostate, as well as other diseases, due to their antioxidant activity. ${ }^{12,13}$

Targeted delivery of chemotherapeutics is one of the main challenges in the treatment of neoplasms of different origin and $\mathrm{BPH}$, and development of treatment strategies to minimize the side effects of drugs is a very active field of research. Targeted delivery can be achieved by application of pharmaceutical nanotechnology, which is based on the development, application, and characterization of nanoscale therapeutic systems that provide more controlled drug release, and this approach is therapeutically relevant. ${ }^{14}$

Poly(lactic-co-glycolic acid) (PLGA) is a biodegradable polymer that is used extensively in the preparation of nanoparticles. ${ }^{15}$ PLGA has been described as an important carrier for water-soluble and poorly soluble drugs because of its excellent biocompatibility and biodegradability and its versatility, allowing for different nanoparticle preparation methods. ${ }^{16,17}$ PLGA nanoparticles have been used for sitespecific delivery of drugs to the brain, arterial walls, lungs, tumor cells, liver, and spleen. They can also be designed for long-term systemic circulation within the body and for numerous routes of delivery. ${ }^{15,18-21}$ According to previous work, poorly water-soluble drugs can be encapsulated by PLGA nanoparticles through nanoprecipitation. ${ }^{16,22}$ Many drugs, such as 9-nitrocamptothecin, ${ }^{23}$ paclitaxel, ${ }^{24}$ and quercetin $^{25}$ have been encapsulated in PLGA nanoparticles designed for cancer therapy.

Nanocomposites of polymers and clays are other examples of nanotechnology applications. The use of smectite clays in pharmaceutical formulations is well known. ${ }^{26,27}$ Viscogel $B 8^{\circledR}$, an organically modified clay, can intercalate simultaneously with hydrophilic polymers and other lipophilic substances, producing nanomaterials. As described previously by our group, the polyvinylpyrrolidone (PVP) Viscogel $\mathrm{B} 8^{\circledR}$ nanocomposite containing babassu oil (BBS) has inhibitory activity toward BPH cells, showing potential applications for different neoplasia cancer treatments. ${ }^{8,28}$ The main objective of this work was the preparation and characterization of PLGA nanoparticles and clay nanosystems containing BBS for the treatment of BPH and evaluation of their applicability as pharmaceutical formulations.

\section{Materials and methods Materials}

Pluronic F-68, PVP K-30 with a molecular weight of 40,000 , trehalose, monobasic sodium phosphate, $2 \mathrm{M}$ trimethylsilyldiazomethane in diethylether, myristic acid, sodium lauryl sulfate, and methyl pentadecanoate standard for gas chromatography (GC) were purchased from Sigma Chemical Co (St Louis, MO, USA). The PLGA used was Resomer 504 (ratio of polylactic acid to polyglycolic acid, 50:50) from Boehringer Ingelheim (Ingelheim, Germany). Methanol, potassium phosphate monobasic, sodium phosphate dihydrate, 37\% hydrochloric acid, dichloromethane, ethyl alcohol, and acetone (Tedia Company Inc, Fairfield, $\mathrm{OH}, \mathrm{USA}$ ) were analytical grade. Magnesium stearate was provided by Mallinckrodt (Charlotte, NC, USA). Montmorillonite Viscogel B8 was purchased from Bentec (Livorno, Italy). Water was obtained from a Milli-Q water purification system (Millipore, Bedford, MA, USA).

\section{Extraction of BBS}

O. speciosa fruits were collected in April 2010 in the state of Piaui, northeastern Brazil, and processed by kernel separation. O. speciosa kernels were peeled and triturated, and then submitted to solvent extraction with ethanol, using cold dynamic maceration to avoid potential degradation of the active constituents. The solvent used in the extraction was fully removed under reduced pressure using a rotary evaporator (Büchi Labortechnik AG, Flawil, Switzerland) at room temperature. The evaporated material was stored in a refrigerator at $4^{\circ} \mathrm{C} \pm 2{ }^{\circ} \mathrm{C}$.

\section{Characterization of BBS}

The fatty acids in BBS were characterized by gas chromatography-mass spectrometry (GC-MS) after esterification of the crude oil using $2 \mathrm{M}$ trimethylsilyldiazomethane in diethyl ether. ${ }^{29}$ The analyses were performed on a Saturn 2000 workstation (Varian Inc, Walnut Creek, CA, USA) that consisted of a Chrompack CP 3800 gas chromatograph and a Saturn 2000R ion-trap detector. The capillary column was a VF-Xms $(25.0 \mathrm{~m} \times 0.2 \mathrm{~mm})$ from Varian. Helium was used as the carrier gas. The temperature was programmed as follows: $0^{\circ} \mathrm{C}-90^{\circ} \mathrm{C}$ (one minute hold), $90^{\circ} \mathrm{C}-230^{\circ} \mathrm{C}$ at $3^{\circ} \mathrm{C}$ per minute, and $230^{\circ} \mathrm{C}-290^{\circ} \mathrm{C}(5$ minute hold $)$. The calibration curve was obtained using myristic acid as the external standard and methyl pentadecanoate as the internal standard with five concentrations of myristic acid between $36 \mu \mathrm{g} / \mathrm{mL}$ and $0.72 \mathrm{mg} / \mathrm{mL}$.

Linear regression analysis was performed using the method of least squares by Microsoft Excel software. Adequacy of fit was assessed from the coefficient of determination $\left(r^{2}\right)$. The repeatability of the method was evaluated by determination of six samples at the working concentration. 
The retention index was calculated using the GC data from a saturated aliphatic carboxylic acid homologous series from $\mathrm{C}_{12}$ to $\mathrm{C}_{22}$, performed using the same column and conditions as those used in the GC analysis of the essential oils. The analyses related to formulation testing were performed using the same method in a Clarus 500 gas chromatograph from PerkinElmer (Waltham, MA, USA) coupled with a flame ionization detector. Methyl pentadecanoate was used as the internal standard in all of the GC analyses.

Nuclear magnetic resonance (NMR) spectra were recorded on a spectrometer (AMX500, Bruker, Karlsruhe, Germany) operating at $500 \mathrm{MHz}$ for the proton nucleus and at $125 \mathrm{MHz}$ for the carbon nucleus. Both ${ }^{1} \mathrm{H}$ and ${ }^{13} \mathrm{C}$ NMR analyses were performed using $\mathrm{CDCl}_{3}$ and tetramethylsilane (as the internal standard).

\section{Nanocomposite preparation}

All BBS-clay nanosystems were obtained by mixing PVP, Viscogel B8, and BBS at a mass ratio of $2: 1: 1$. Intercalation was induced by solubilizing $2 \mathrm{~g}$ of PVP in $150 \mathrm{~mL}$ of dichloromethane, then adding $1 \mathrm{~g}$ of BBS and $1 \mathrm{~g}$ of Viscogel B8. A homogeneous suspension was formed and kept under magnetic stirring for 72 hours. Aliquots of the suspension were taken at one, 24, and 72 hours, and subsequently referred to as samples $\mathrm{T}_{0}, \mathrm{~T}_{1}$, and $\mathrm{T}_{2}$, respectively. These aliquots were centrifuged to remove adsorbed BBS, ie, BBS not included in the interlamellar spacing. The pellet was resuspended in dichloromethane and then evaporated under vacuum at $45^{\circ} \mathrm{C}$. The powdered nanocomposite was then taken to calculate the BBS intercalation yields by GC-MS analysis and to prepare the capsules. All nanocomposites were prepared in triplicate to confirm reproducibility of the method. For comparison, the physical mixtures were produced from pure material powder blends without any special treatment.

\section{Nanocomposite characterization}

The median particle size diameter distribution of Viscogel B8 was measured by laser diffraction with a Mastersizer 2000 equipped with a Scirocco dry powder feeder (Malvern Instruments Ltd, Malvern, UK). The nanocomposites were characterized by X-ray diffraction, thermogravimetric analysis, differential scanning calorimetry, and Fourier transform infrared spectroscopy. The samples were dried, powdered, and sieved using a 40 mesh sieve for X-ray diffraction analysis at room temperature by a Rigaku MiniFlex II diffractometer (The Woodlands, TX, USA). The diffraction angle range $(2 \theta)$ was $2^{\circ}-20^{\circ}$, with a scan speed of one degree per minute, and $\mathrm{CuK} \alpha$ radiation was used as the
X-ray source and operated at $40 \mathrm{kV}$ and $30 \mathrm{~mA}$. Interlamellar spacings were calculated using the Bragg equation $(\lambda=2 d$ $\sin \theta$, where $\lambda$ is the X-ray wavelength, $2 d$ is the interlamellar spacing, and $\theta$ is the incident angle). Calorimetric studies were performed on an differential scanning calorimeter and thermogravimetry was performed on a thermogravimetric analyzer (822e and SDTA 851e, respectively, Mettler Toledo, Greifensee, Switzerland) using standard aluminum crucibles, with a nitrogen flow of $50 \mathrm{~mL}$ per minute, a heating rate of $20^{\circ} \mathrm{C}$ per minute, and temperature ranges of $25^{\circ} \mathrm{C}-300^{\circ} \mathrm{C}$ for differential scanning calorimetry and $25^{\circ} \mathrm{C}-800^{\circ} \mathrm{C}$ for thermogravimetric analysis. Fourier transform infrared spectrophotometry was applied to the nanocomposite analysis using the attenuated total reflection technique. Samples (1\%, w/w) were prepared by the KBr pellet method. The analyses were carried out using a spectrophotometer (IR Prestige 21, Shimadzu, Kyoto, Japan).

\section{Preparation and characterization of capsule containing BBS nanocomposite}

The hard gelatin capsules were prepared by filling with nanocomposite powders or equivalent physical mixtures passed through a 40 mesh sieve. The lubrificant in both cases was magnesium stearate $(1.0 \%, \mathrm{w} / \mathrm{w})$. The nanoparticles were characterized for dose uniformity, BBS content, and mean weight. ${ }^{30,31}$

\section{Drug release from BBS nanocomposite capsules}

Release tests for the BBS nanocomposite capsules were performed using a US Pharmacopeia SR8-Plus dissolution test station from Hanson Research (Chatsworth, CA, USA). ${ }^{31}$ The equipment was used with a sinker, at a paddle rotation speed of $75 \mathrm{rpm}$, in $900 \mathrm{~mL}$ of simulated gastric fluid (USP 33) and 1\% (w/v) sodium lauryl sulfate at a temperature of $37^{\circ} \mathrm{C} \pm 0.5^{\circ} \mathrm{C}$. At 30,60 , and 120 minutes, $10 \mathrm{~mL}$ samples were withdrawn from the dissolution vessels, and the concentration of BBS was measured by GC-flame ionization detection after three cycles of liquid-liquid extraction of BBS in ether.

The average particle size of the nanocomposite dispersed in each dissolution aliquot collected at 30, 60, and 120 minutes was measured immediately using a laser diffraction particle size analyzer (Mastersizer 2000) equipped with a Hydro $2000 \mu \mathrm{P}$ accessory (Malvern Instruments Ltd). Each dissolution aliquot was dispersed in Milli-Q water under stirring $(1,000 \mathrm{rpm})$ until the required obscuration $(5 \%-25 \%)$ was reached. 


\section{Preparation of PLGA-BBS nanoparticles}

The PLGA-BBS nanoparticles were prepared according to the precipitation-solvent evaporation method described by Fessi et al. ${ }^{22} \mathrm{BBS}$ was dissolved in acetone under magnetic stirring followed by addition of PLGA. This solution was poured into the Pluronic F-68 solution with moderate stirring at room temperature. Nanoparticles were formed immediately, and the acetone was evaporated using a rotary evaporator (Büchi Labortechnik AG, Flawil, Switzerland) under reduced pressure at room temperature. The PLGA-BBS nanoparticle concentrations were varied from $100 \mathrm{mg}$ to $250 \mathrm{mg}$ of PLGA using $50 \mathrm{mg}$ of BBS. The nanoparticles were lyophilized with a cryoprotectant using $5 \%(\mathrm{w} / \mathrm{v})$ trehalose. Trehalose powder was directly dissolved in the nanoparticle dispersion under stirring after acetone had been evaporated. The samples were then frozen using liquid nitrogen, followed by lyophilization at $-50^{\circ} \mathrm{C}$ to $-55^{\circ} \mathrm{C}$ for 48 hours at $5 \mathrm{~Pa}$ (VirTis $6 \mathrm{~K}$ freezedryer model EL, SP Scientific, Warminster, PA, USA). The lyophilized samples were stored at $-20^{\circ} \mathrm{C}$ until further characterization. The samples were reconstituted at room temperature to the original volume using Milli-Q water.

\section{Characterization of PLGA-BBS nanoparticles}

The mean diameter, polydispersity index, and zeta potential of the samples were analyzed using a Zetasizer Nano ZS (Malvern Instruments Ltd). All measurements were performed on fresh and reconstituted samples after lyophilization. The mean nanoparticle diameter of the reconstituted samples after lyophilization was corrected by the medium viscosity measured in a low frequency vibration viscometer for each formulation after reconstitution
(SV-10 Vibro Viscometer, A\&D Company Ltd, Griesheim, Germany). ${ }^{32}$ The morphologic characteristics of the nanoparticles were viewed under a MIRA3 variable pressure field emission scanning electron microscope (Tescan, BrnoKohoutovice, Czech Republic) at an accelerating voltage of $5.0 \mathrm{kV}$. The fresh samples were applied onto aluminum stubs, dried, and sputter-coated with gold. The BBS loading in the PLGA nanoparticles was determined by CG-flame ionization detection after ultracentrifugation at 30,000 rpm for 40 minutes and pellet dissolution in acetone.

BBS release from the PLGA nanoparticles was determined using $150 \mathrm{mg}$ of fresh sample under stirring in $5.0 \mathrm{~mL}$ of phosphate buffer $(\mathrm{pH} 7.4)$ at $37^{\circ} \mathrm{C}$ containing $0.5 \% \mathrm{w} / \mathrm{w}$ sodium lauryl sulfate. After 48 hours of analysis, the solution was centrifuged at $30,000 \mathrm{rpm}$ for 40 minutes. The pellet was resuspended in acetone, and the amount of BBS was determined by CG-flame ionization detection. The BBS released was calculated by comparing to the amount of BBS loaded into nanoparticles, considered as $100 \%$.

\section{Results and discussion}

\section{Extraction and characterization of BBS}

After the babassu kernel extraction process, a viscous white oil was obtained that solidified at room temperature (extraction yield $8 \% \mathrm{w} / \mathrm{w}$ ). ${ }^{1} \mathrm{H}$ NMR and ${ }^{13} \mathrm{C}$ NMR spectra showed a predominance of aliphatic, $\alpha$-carboxyl, and vinyl hydrogens and the respective carbon atoms (Figure 1). The chromatographic profile of the oil after methylation showed the presence of even-chain carboxylic acids (Figure 2). Myristic acid was used as the external standard due to its abundance in the oil $17.92 \% \pm 0.25 \%$, and the internal standard, methyl pentadecanoate, was chosen because of
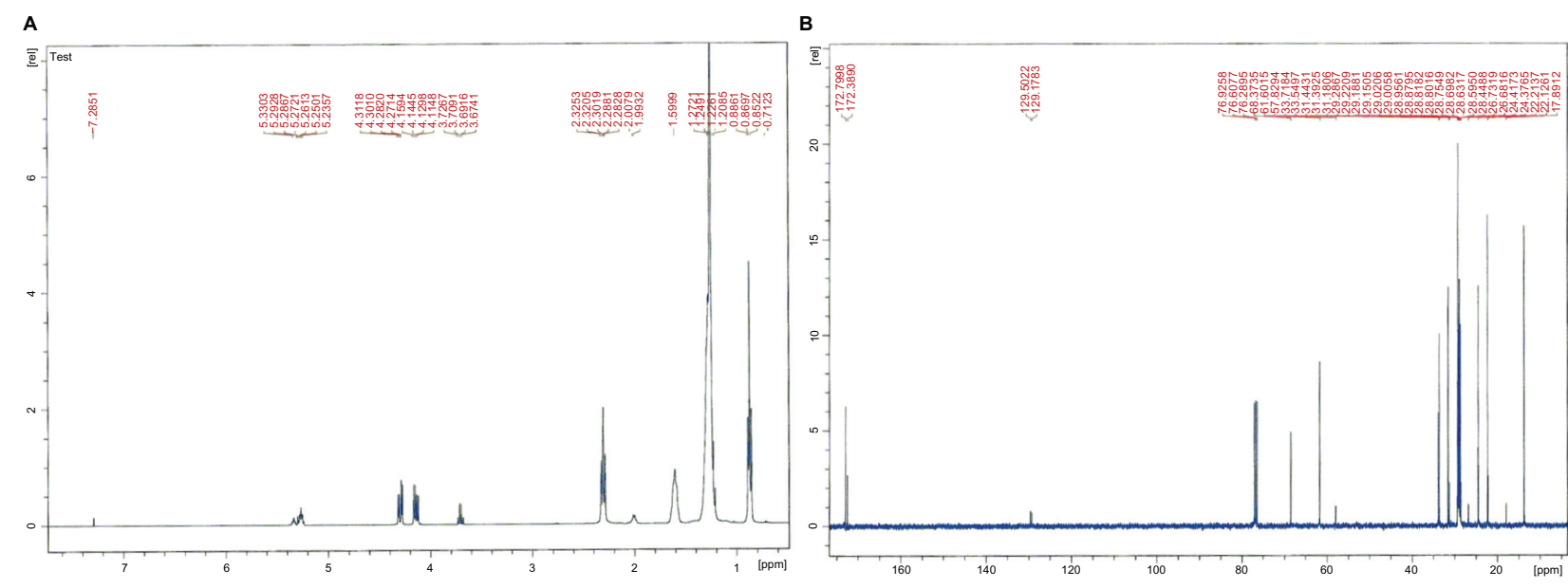

Figure I 'H NMR (A) and ${ }^{13} \mathrm{C}$ NMR (B) spectra for babassu oil. Abbreviation: NMR, nuclear magnetic resonance. 


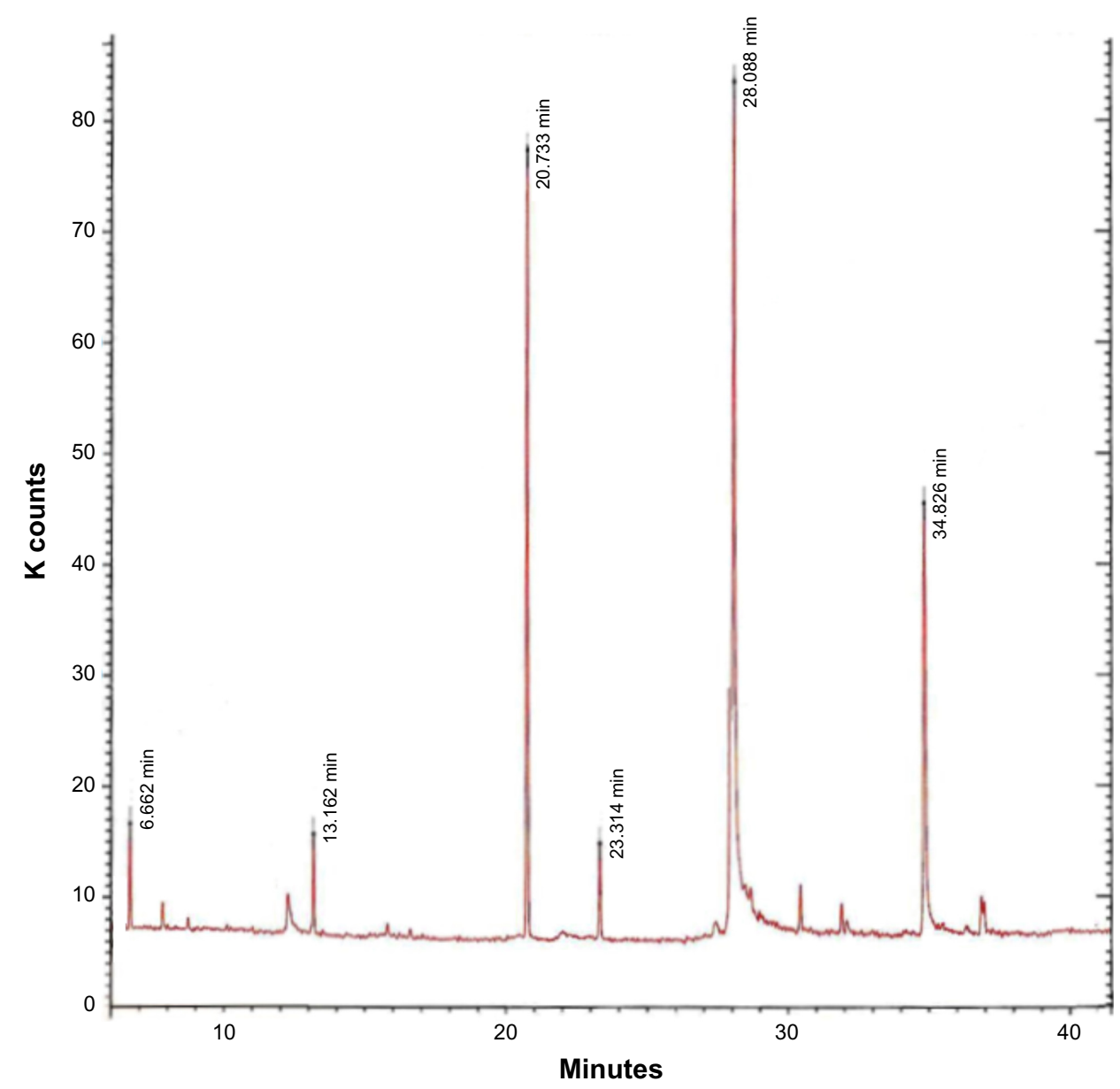

Figure 2 Gas chromatographic-mass spectrometric image of babassu oil. Abbreviation: min, minutes.

the absence of odd-chain fatty acids in BBS..$^{33}$ The retention time of the external and internal standard was 28.0 minutes and 31.5 minutes, respectively. The calibration curve was performed at five levels on 3 consecutive days using the internal standardization method. The calculated slope was $11.314 \pm 0.343$ and the intercept was $0.1703 \pm 0.0064$ (average \pm relative standard deviation). The linearity was adequate $\left(r^{2}=0.9991\right)$. The intraday precision, determined by the relative standard deviation of six analyses of samples at the working concentration, was $0.56 \%$. This value was accurate and linear over the range of concentrations used. ${ }^{34}$ The amount of myristic acid per mg of BBS was calculated to be 17.9 throughout the analyses, using the linear regression method. This index was used for calculation of BBS loading into the nanosystems prepared.

\section{Characterization of nanocomposites}

The results of the particle size distribution analysis obtained by laser diffraction for the Viscogel B8 dry powder show that the median diameter of the particles was $1.90 \mu \mathrm{m}$ and that $90 \%$ had diameters less than $4.77 \mu \mathrm{m}$, confirming the clay microstructure reported in the literature. ${ }^{35}$ The spacing between the clay layers in the products obtained was evaluated by X-ray diffraction analysis, which showed an increase in the clay basal spacing as a consequence of oil and PVP intercalation. ${ }^{36}$ As observed in Table 1, the nanosystem interlamellar spacing obtained was approximately $41 \AA$ for the $\mathrm{T}_{0}$ (the same value observed for $\mathrm{T}_{1}$ and $\mathrm{T}_{2}$ ) while the clay basal spacing

Table I Interlamellar spacing obtained for the clay, clay-polymer, and nanocomposite containing BBS

\begin{tabular}{lll}
\hline Sample & $\mathbf{2 \theta}$ & $\mathbf{A}$ \\
\hline VB8 & 3.3 & 26.50 \\
VB8 + PVP & 2.6 & 33.98 \\
Nano $T_{0}$ & 2.15 & 41.09 \\
Nano T & 2.09 & 39.94 \\
Nano T $_{2}$ & 2.21 & 42.23 \\
\hline
\end{tabular}

Note: Mean, $\mathrm{n}=3$.

Abbreviations: BBS, babassu oil; VB8, montmorillonite Viscogel B8 ${ }^{\circledR}$; PVP, polyvinylpyrrolidone K-30; Nano $T_{0}$, BBS nanocomposite reacted during one hour; Nano $T_{1}$, BBS nanocomposite reacted during 24 hours; Nano $\mathrm{T}_{2}$, BBS nanocomposite reacted during 72 hours. 


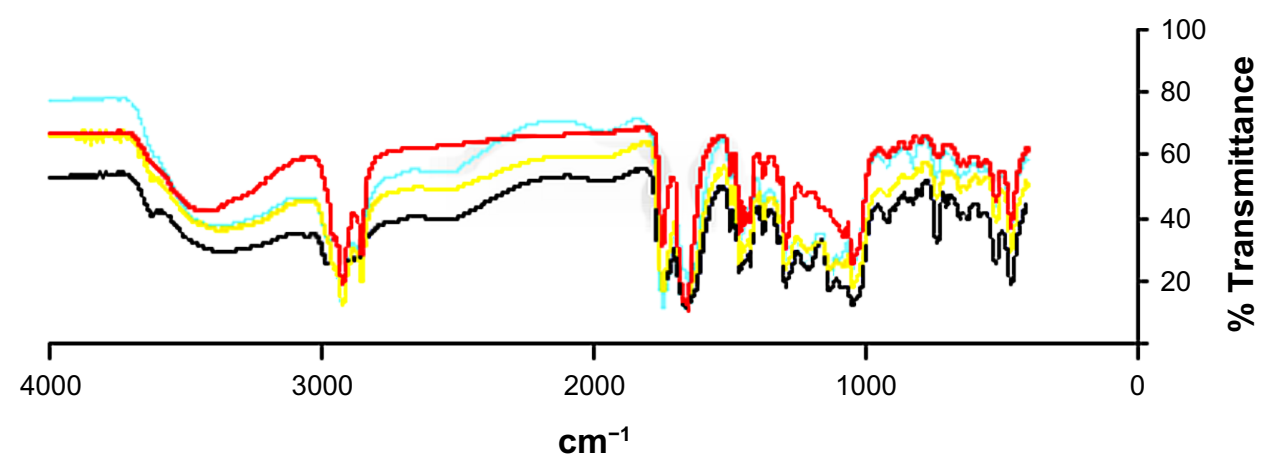

Figure 3 Fourier transform infrared spectrum of VB8:PVP (blue) and nanocomposite (ratio of VB8 to PVP to BBS, I:2:1) at different reaction times, ie, $T_{0}$ (black), $T_{1}$ (yellow), and $\mathrm{T}_{2}$ (red).

Abbreviations: BBS, babassu oil; PVP, polyvinylpyrrolidone; VB8, Viscogel B8 ${ }^{\circledR}$.

was approximately $26.5 \AA$. The clay-polymer basal spacing obtained by intercalation of PVP was approximately $34 \AA$. These results are in accordance with the literature and indicate the success of the intercalation process. ${ }^{35,36}$ This increase in the interlayer spacing of the BBS-clay-polymer suggests intercalation of BBS into the interlayer of the clay-polymer. The presence of BBS in the nanosystem was confirmed by Fourier transform infrared spectroscopy (Figure 3), which showed a significant increase in absorption at $1,600-1,750 \mathrm{~cm}^{-1}$ and $1,000-1,150 \mathrm{~cm}^{-1}$ due to carbonyl stretching and the carboxyl groups of the fatty acids present in the oil. Thermal analysis of the nanocomposite was performed by differential scanning calorimetry and thermogravimetric analysis (Figures 4 and 5). The differential scanning calorimetry curves for the BBS

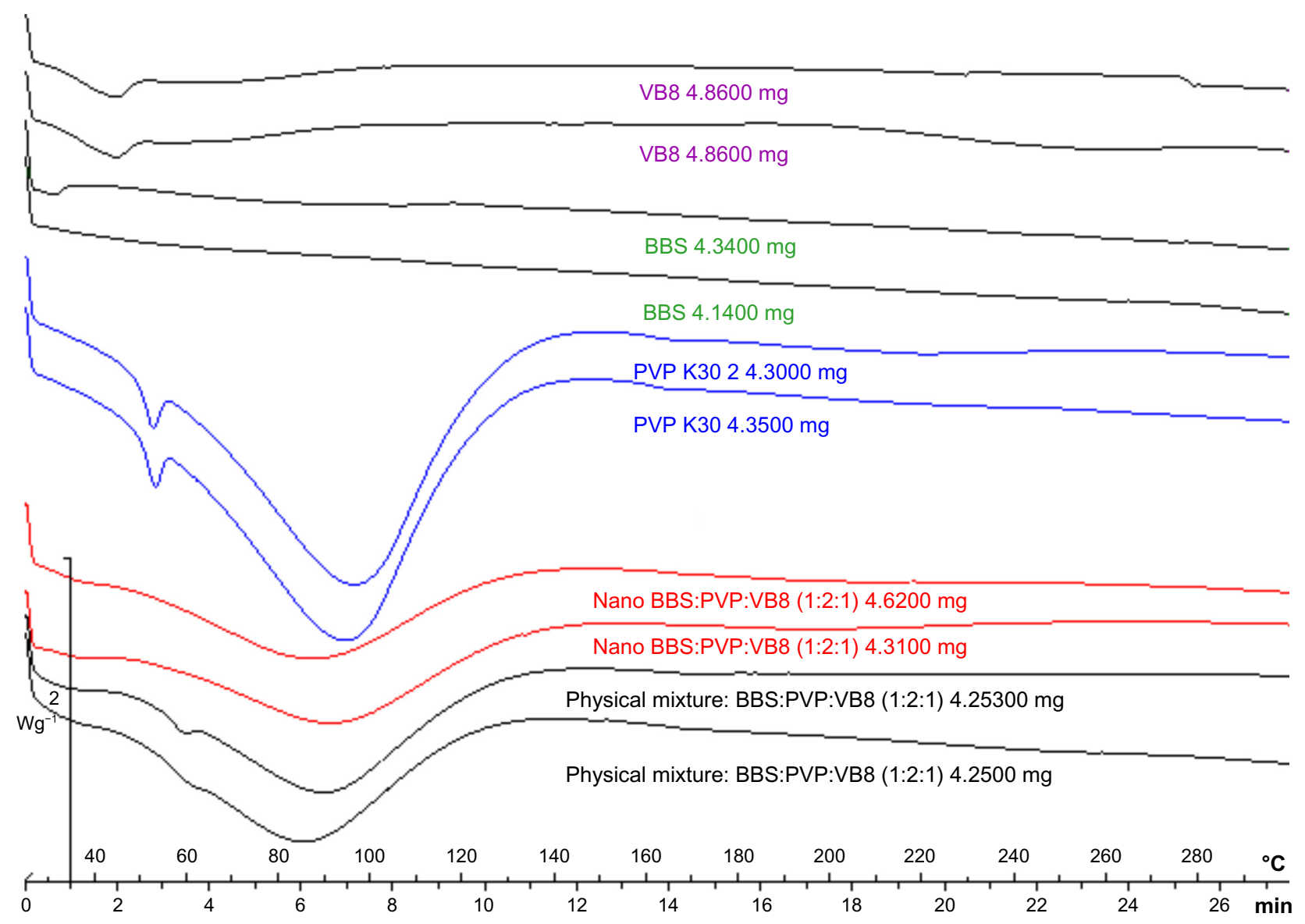

Figure 4 Differential scanning calorimetric thermograms for VB8, BBS extract, PVP, BBS nanocomposite ( $\left.T_{0}\right)$, and an equivalent physical mixture of the nanocomposite components (ratio of VB8 to PVP to BBS, I:2:1).

Abbreviations: BBS, babassu oil; PVP, polyvinylpyrrolidone; VB8, Viscogel B8 ${ }^{\circledR}$; min, minutes. 

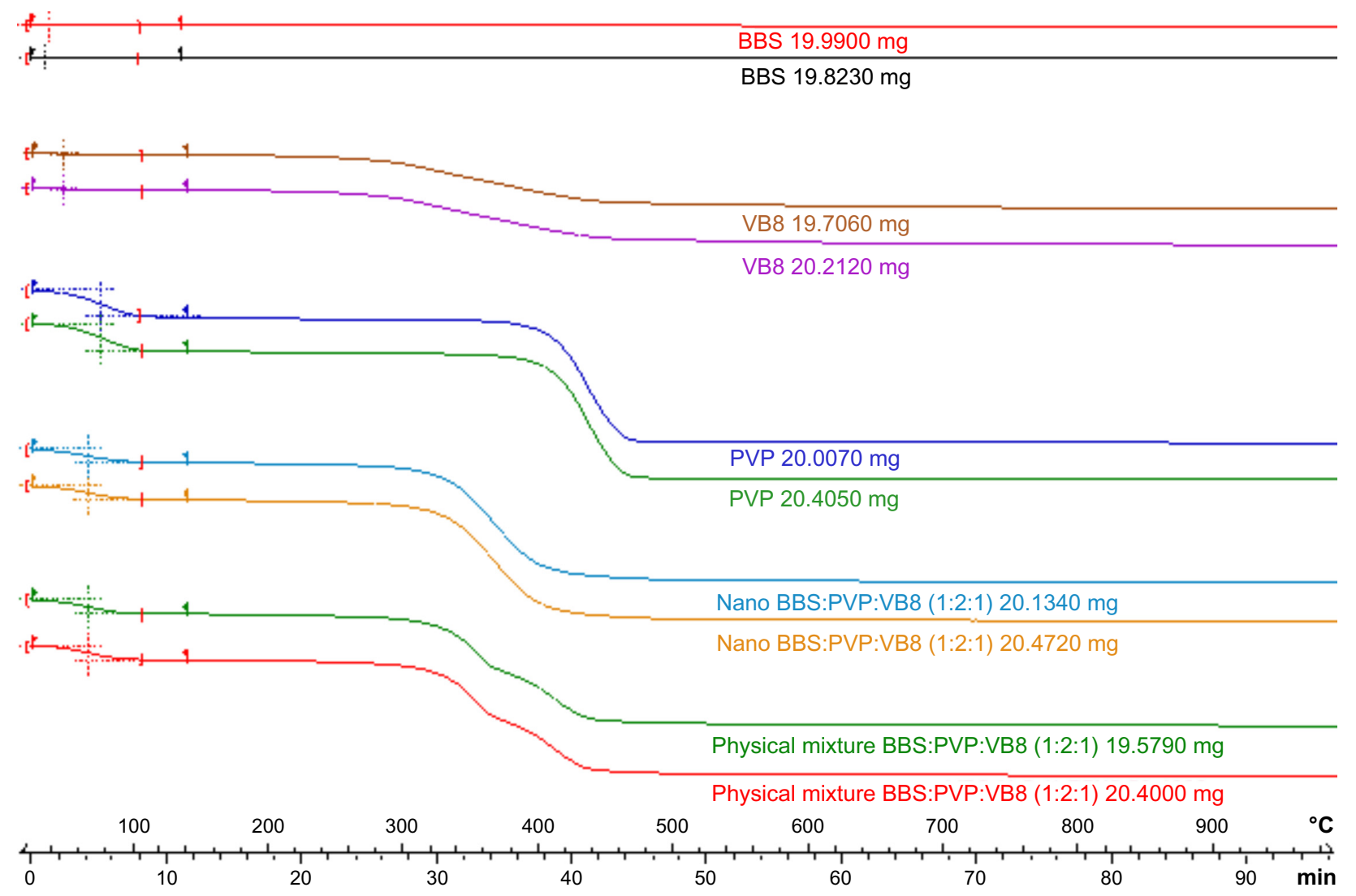

Figure 5 Thermogravimetric analysis curves for BBS extract, VB8, PVP, BBS nanocomposite $\left(\mathrm{T}_{0}\right)$ and an equivalent physical mixture of the nanocomposite components (PVP, VB8, and BBS).

Abbreviations: BBS, babassu oil; PVP, polyvinylpyrrolidone; VB8, Viscogel B8 ${ }^{\circledR}$; min, minutes.

nanocomposite shown in Figure 4 indicate disappearance of the endothermic peak, which corresponds to polymer dehydration at approximately $65^{\circ} \mathrm{C}$ in the formed nanosystem, and displacement of the endotherm related to water loss at $80^{\circ} \mathrm{C}$ in comparison with the physical mixture compatible with insertion of a more lipophilic material in the PVP matrix. Absence of this endotherm is associated with insertion of PVP into the interlamellar space in combination with BBS extract, unlike what is observed in both the physical mixture and the polymer alone, indicating the nanocomposite obtention. In the physical mixture and in the nanocomposite analysis it is not possible to observe the endotherm related to the PVP glass transition temperature. The thermogravimetric analysis curves in Figure 5 show that the weight loss from nanosystem started at $320^{\circ} \mathrm{C}$ and ended at $420^{\circ} \mathrm{C}$, whereas for the equivalent physical mixture these temperatures were $300^{\circ} \mathrm{C}$ and $420^{\circ} \mathrm{C}$, respectively. PVP and VB8 did not show significant weight loss in this temperature range, only presenting about $14.0 \%$ of water loss at $390 \mathrm{oC}$. The nanosystem presented good thermal stability without indication of BBS degradation. The thermogravimetric analysis and differential scanning calorimetry curves indicate formation of the nanocomposite. Determination of the yield of BBS incorporation into the nanocomposite was performed by GC-MS. The inclusion yield was $98.7 \%$ for the shortest reaction time (one hour, $\mathrm{T}_{0}$ ) and this was selected as optimal for preparation of the BBS-clay-polymer nanocomposite.

\section{Characterization of BBS nanocomposite capsules}

The nanocomposites showed visually high fluidity during the encapsulation process in the hard gelatin capsule. This behavior was not observed for physical mixtures that showed particle

Table 2 Particle size distribution by laser diffraction and BBS released (as assayed by gas chromatography) from the capsules containing the nanocomposite in the dissolution test

\begin{tabular}{lllll}
\hline $\begin{array}{l}\text { Time } \\
\text { (minutes) }\end{array}$ & \multicolumn{3}{l}{ Particle size distribution $(\mu \mathrm{m})$} & BBS \\
\cline { 2 - 4 } & $\mathbf{d}(\mathbf{0 . 1})$ & $\mathbf{d}(\mathbf{0 . 5})$ & $\mathbf{d}(\mathbf{0 . 9})$ & released (\%) \\
\hline 30 & $\mathrm{I}, 260.4$ & $\mathrm{I}, 348.8$ & $\mathrm{I}, 672.2$ & - \\
60 & 5.6 & 34.7 & $1,557.4$ & $50.73 \pm 12.97$ \\
120 & 4.9 & 18.3 & 48.8 & $89.12 \pm 18.58$ \\
\hline
\end{tabular}

Note: ${ }^{\text {Mean }} \pm$ relative standard deviation, $(n=6)$.

Abbreviations: $B B S$, babassu oil; $d(0.1), 10 \%$ of volume distribution is below this value; $\mathrm{d}(0.5), 50 \%$ of volume distribution is below this value; $\mathrm{d}(0.9), 90 \%$ of volume distribution is below this value. 
Table 3 Mean particle size, polydispersity index, and zeta potential of PLGA nanoparticles immediately after preparation, on the third day, and after lyophilization

\begin{tabular}{|c|c|c|c|c|c|}
\hline & \multirow[t]{2}{*}{ PLGA-BBS $^{\mathbf{a}}$} & \multirow[t]{2}{*}{ Parameters } & \multicolumn{2}{|c|}{ Before lyophilization } & \multirow[t]{2}{*}{ After lyophilization } \\
\hline & & & Day I & Day 3 & \\
\hline \multirow[t]{3}{*}{ Control } & I50 mg:- & $\mathrm{MD}(\mathrm{nm})$ & $226.4 \pm 1.64$ & $201.8 \pm 0.935$ & $243.9 \pm 2.55$ \\
\hline & & PD & $0.060 \pm 0.023$ & $0.053 \pm 0.026$ & $0.201 \pm 0.016$ \\
\hline & & $\mathrm{ZP}(\mathrm{mV})$ & $-30.9 \pm 0.304$ & $-14.1 \pm 0.484$ & $-10.5 \pm 0.128$ \\
\hline \multirow[t]{3}{*}{$\mathrm{Npl}$} & $250 \mathrm{mg}: 50 \mathrm{mg}$ & $\mathrm{MD}(\mathrm{nm})$ & $295.0 \pm 2.20$ & $288.8 \pm 3.18$ & $355.3 \pm 5.50$ \\
\hline & & $\mathrm{PD}$ & $0.246 \pm 0.016$ & $0.165 \pm 0.006$ & $0.295 \pm 0.009$ \\
\hline & & $\mathrm{ZP}(\mathrm{mV})$ & $-44.0 \pm 1.14$ & $-12.9 \pm 1.08$ & $-8.69 \pm 1.01$ \\
\hline \multirow[t]{3}{*}{$\mathrm{Np} 2$} & $150 \mathrm{mg}: 50 \mathrm{mg}$ & $\mathrm{MD}(\mathrm{nm})$ & $262.2 \pm 1.41$ & $244.4 \pm 2.72$ & $360.1 \pm 6.52$ \\
\hline & & $\mathrm{PD}$ & $0.168 \pm 0.013$ & $0.139 \pm 0.022$ & $0.423 \pm 0.011$ \\
\hline & & $\mathrm{ZP}(\mathrm{mV})$ & $-44.0 \pm 0.683$ & $-10.3 \pm 0.866$ & $-2.43 \pm 0.189$ \\
\hline \multirow[t]{3}{*}{ Np3 } & $100 \mathrm{mg}: 50 \mathrm{mg}$ & $\mathrm{MD}(\mathrm{nm})$ & $271.0 \pm 3.38$ & $247.4 \pm 1.61$ & $259.7 \pm 2.4 I$ \\
\hline & & PD & $0.195 \pm 0.005$ & $0.147 \pm 0.035$ & $0.234 \pm 0.017$ \\
\hline & & $\mathrm{ZP}(\mathrm{mV})$ & $-41.0 \pm 0.267$ & $-|7.4 \pm 0.64|$ & $-13.9 \pm 1.44$ \\
\hline
\end{tabular}

Notes: Mean \pm standard deviation $(\mathrm{n}=3$ ). aPLGA:drug was dissolved in $5 \mathrm{~mL}$ of acetone, poured into $30 \mathrm{~mL}$ of Pluronic $0.5 \% \mathrm{w} / \mathrm{v}$.

Abbreviations: BBS, babassu oil; MD, mean diameter (calculated as z-average); Np, nanoparticle; PD, polydispersity index; PLGA, poly(lactic-co-glycolic acid); ZP, zeta potential.

stickiness, which is not adequate for an efficient encapsulation or compression process. This difference is also evidence of the formation of a new material. The nanocomposite capsules had a mean weight of $647.5 \pm 2.59 \mathrm{mg}$ and a mean BBS content of $159.05 \pm 4.21 \mathrm{mg}$, which is consistent with the PVP to Viscogel B8 to BBS ratio $(2: 1: 1 ; \mathrm{w} / \mathrm{w})$, indicating $25 \% \mathrm{w} / \mathrm{w}$ of BBS per capsule.

\section{Release of BBS from nanocomposite capsules}

Dissolution of the nanocomposite capsules showed a high BBS release in simulated gastric fluid, especially given its predominantly lipid composition. Approximately $89.1 \%$ of the intercalated BBS was released within 120 minutes (Table 2). The results of average particle diameter analysis of the nanocomposite remaining in the dissolution test showed that smaller particles were found when BBS was practically fully released. Submicron particles $(0.542 \mu \mathrm{m})$ were observed after 420 minutes in the dissolution test. Thus, when the nanomaterial was divided into fine particles in the dissolution medium, BBS was released (Table 2). This result demonstrates the efficiency of the nanocomposites in enhancing release of BBS, potentially indicating adequate gastrointestinal absorption and action at BPH cell sites. This result is in accordance with other studies showing the efficiency of sustained intestinal delivery of drugs using intercalation of drugs within the interlayer space of montmorillonite as a drug delivery device. ${ }^{35-38}$

\section{Characterization of PLGA-BBS nanoparticles}

The nanoparticles were obtained using the nanoprecipitation method. ${ }^{16,22}$ Solvents, ie, dichloromethane, ethyl acetate, and acetone, were tested to obtain nanoparticles with the required properties. Acetone was the solvent that best solubilized BBS and PLGA, and has less toxicity and poses a lower risk to human health than the other solvents. The volatility of acetone accelerated the process of nanoparticle preparation, creating a system with greater uniformity. ${ }^{39,40}$ As shown in Table 3, PLGA to BBS weight ratios of 5:1, 3:1, and 2:1 were evaluated. All the ratios were effective in formation of nanoparticles in terms of the measured size distribution. The sizes of the particles remained stable even after 3 days of preparation. After this period, the nanoparticles were lyophilized using 5\% $\mathrm{w} / \mathrm{v}$ trehalose as a cryoprotectant. The particle sizes after lyophilization were approximately $355 \mathrm{~nm}, 360 \mathrm{~nm}$, and $260 \mathrm{~nm}$ for $\mathrm{Np}$ (nanoparticle)1, 2, and 3, respectively (Table 3). The results show that varying the ratio of PLGA to BBS caused a slight change in the dimensions and other measured properties of the nanoparticles (Table 3). However, during preparation of the nanoparticles, significant aggregation of PLGA was detected visually when 5:1 and 3:1 mass ratios were used. BBS loading was less than $10 \%$ for all of the tested ratios. The nanoparticles with a ratio of PLGA of BBS of 2:1 showed the least

Table 4 Composition of nanoparticles based on the $\mathrm{Np} 3$ formulation

\begin{tabular}{llllll}
\hline Components & Np3a & Np3b & Np3c & Np3d & Np3e \\
\hline BBS $(\mathrm{mg})$ & 50 & 50 & 50 & 50 & 50 \\
PLGA (mg) & 100 & 100 & 100 & 100 & 100 \\
$\begin{array}{l}\text { Acetone }(\mathrm{mL}) \\
\text { Pluronic }\end{array}$ & 5 & 5 & 10 & 10 & 10 \\
$\quad(\mathrm{~mL})$ & 30 & 30 & 30 & 15 & 15 \\
$(\%)$ & 0.5 & $\mathrm{I}$ & 0.5 & 0.5 & $\mathrm{I}$ \\
\hline
\end{tabular}

Abbreviations: BBS, babassu oil; $\mathrm{Np}$, nanoparticle; PLGA, poly(lactic-coglycolic acid). 
Table 5 Mean particle size, polydispersity index, and zeta potential of BBS-PLGA nanoparticles based on Np3 formulation

\begin{tabular}{llllll}
\hline Parameters & Np3a & Np3b & Np3c & Np3d & Np3e \\
\hline 0 day & & & & & \\
MD $(\mathrm{nm})$ & $256.1 \pm 0.846$ & $262.3 \pm 1.10$ & $221.7 \pm 3.72$ & $209.2 \pm 1.31$ & $278.4 \pm 3.80$ \\
PD & $0.260 \pm 0.008$ & $0.196 \pm 0.008$ & $0.181 \pm 0.012$ & $0.145 \pm 0.010$ & $0.130 \pm 0.005$ \\
ZP $(\mathrm{mV})$ & $-45.4 \pm 0.821$ & $-37.6 \pm 0.350$ & $-32.3 \pm 0.466$ & $-15.8 \pm 1.03$ & $-22.7 \pm 0.530$ \\
$\mathbf{7}$ days & & & & & \\
MD $(\mathrm{nm})$ & $220.5 \pm 1.98$ & $294.5 \pm 4.36$ & $225.7 \pm 0.720$ & $208.1 \pm 1.44$ & $252.2 \pm 1.48$ \\
PD & $0.132 \pm 0.027$ & $0.173 \pm 0.017$ & $0.164 \pm 0.014$ & $0.249 \pm 0.003$ & $0.214 \pm 0.022$ \\
ZP $(\mathrm{mV})$ & $-27.7 \pm 0.851$ & $-18.7 \pm 0.918$ & $-21.8 \pm 0.380$ & $-13.9 \pm 1.04$ & $-27.5 \pm 0.477$ \\
\hline
\end{tabular}

Note: Mean \pm standard deviation $(n=3)$.

Abbreviations: BBS, babassu oil; MD, mean diameter (calculated as z-average); Np, nanoparticle; PD, polydispersity index; PLGA, poly(lactic-co-glycolic acid); ZP, zeta potential.

visible agglomeration. Due to the lesser aggregation observed for the 2:1 ratio, this formulation was submitted to different protocols (Table 4) to optimize the process by reducing loss of PLGA by agglomeration. PLGA loss was addressed by increasing the volume of acetone used to dissolve the PLGA (Np3c, Np3d, and Np3e). The concentration and volume of the Pluronic solution were also tested, but its influence on particle size was minor. Using $10 \mathrm{~mL}$ of acetone and $0.5 \%$ w/v Pluronic (Np3c and Np3d), nanoparticle suspensions were formed with suitable diameters (Table 5). A larger amount of acetone was necessary to increase BBS loading because all of the nanoparticles prepared with $5 \mathrm{~mL}$ of acetone had less than 10\% BBS loading. The Np3c and Np3d formulations had a lower mean particle size that was maintained for 7 days of storage with a suitable polydispersity index (Table 5). Loadings in excess of $90 \%$ were achieved for $\mathrm{Np} 3 \mathrm{c}$ and $\mathrm{Np} 3 \mathrm{~d}$ (Table 6). Figure 6 shows scanning electron micrographs of the $\mathrm{Np} 3 \mathrm{c}$ and $\mathrm{Np} 3 \mathrm{~d}$ nanoparticles. The nanoparticle images show a spherical morphology, highly regular, and adequate to vectorize BBS for BPH cells.

\section{Potential applications in BPH therapy}

Nanoparticles act as potential carriers for several classes of drugs and macromolecules, and more recently, for plant extracts. ${ }^{41}$ The long-term effect of single and combination therapy with synthetic drugs and surgical removal of the prostate do not indicate unequivocal improvement in quality of life for a man with BHP. ${ }^{1,42} \mathrm{BPH}$ is a disease associated

Table 6 Quantity of BBS included in the preparation process for nanoparticles and percentage of BBS loading in Np3c and Np3d

\begin{tabular}{lll}
\hline Formulation & Initial BBS mass $\mathbf{( m g )}$ & Loading $(\%)$ \\
\hline $\mathrm{Np3c}$ & 55.9 & $95.31 \pm 1.22$ \\
$\mathrm{Np3d}$ & 70.0 & $90.97 \pm 1.14$ \\
\hline
\end{tabular}

Note: Mean \pm standard deviation $(n=3)$.

Abbreviations: BBS, babassu oil; Np, nanoparticle. with a significant inflammatory component. The previously described anti-inflammatory and antiproliferative effects of BBS in cells indicate that its use in nanosystems could be effective in treating this disease, and with fewer side effects..$^{5-9}$ The nanotechnology approach to BPH therapy has not been studied, despite being promising by providing more

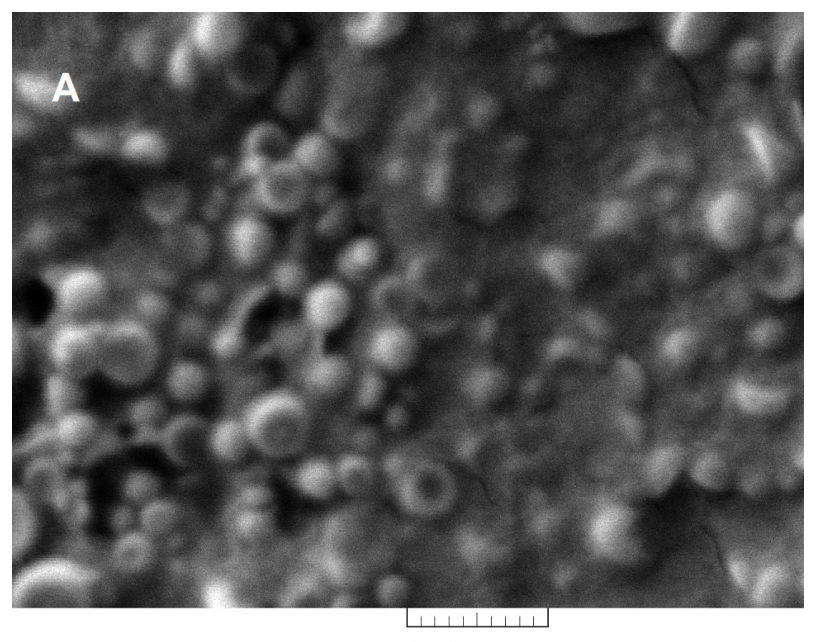

$500 \mathrm{~nm}$

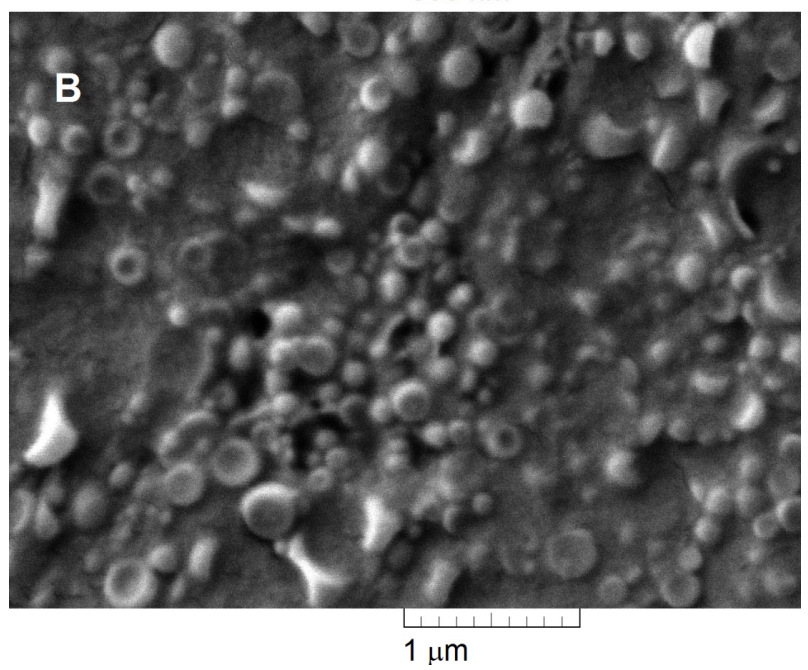

Figure 6 Scanning electron micrographs of $\mathrm{Np} 3 \mathrm{c}(\mathbf{A})$ and $\mathrm{Np} 3 \mathrm{~d}(\mathbf{B})$. Abbreviation: Np, nanoparticle. 
controlled drug release and reducing the frequency of drug administration. Our group investigated the in vitro effect of a BBS nanocomposite on BPH stromal cell and tissue cultures, focusing on morphologic changes, proliferation, viability, necrosis, and induction of apoptosis. ${ }^{8}$ The results showed in vitro evidence that this nanosystem exerts antiproliferative and apoptotic effects in BPH primary cell and tissue cultures, demonstrating that nanosized drug delivery systems can be a valuable alternative approach to treating $\mathrm{BPH}{ }^{8}$ In vivo studies must be performed with the BBS nanocomposite in order to confirm its therapeutic efficacy.

PLGA has been used as a delivery vehicle for chemotherapeutic drugs, and studies have demonstrated that these nanocarriers can significantly enhance the antitumor efficiency of such drugs. ${ }^{23-25}$ PLGA allows extended release of loaded molecules as well as vectorization of the drug, and these properties make this polymer very attractive in the treatment of BPH. ${ }^{18-21}$ Verma et al evaluated the biological safety of PLGA nanocarriers by investigating in vitro cell-nanosystem interactions with a focus on cellular accumulation and cytocompatibility in human cells. The in vivo biocompatibility of PLGA nanoparticles was also shown using a mouse model to evaluate oxidative stress. ${ }^{43}$ The biocompatibility and therapeutic efficacy of PLGA-BBS nanoparticles demonstrated in this work will be tested in a separate study.

\section{Conclusion}

In this work, two BBS-containing nanostructured systems were developed. These nanosystems were obtained by intercalation of BBS in the interlamellar spaces of the nanocomposites containing PVP and Viscogel B8 and by encapsulation of BBS in PLGA nanoparticles. Both systems had BBS incorporation rates higher than $90 \%$. The systems differed in extent of BBS release. The PLGA-BBS nanoparticles could be expected to have a prolonged release profile compared with the BBS nanocomposite, which showed rapid drug release. To determine the effectiveness and cytocompatibility of PLGA-BBS nanoparticles, in vitro studies would be required using a cell line, such as BPH, as performed for the BBS nanocomposite. The combination of the two obtained systems at the same dosage must be tested in models as new therapy for BPH.

\section{Acknowledgments}

This work was supported by FAPERJ (Foundation for Research Support of the State of Rio de Janeiro), CAPES Edital Nanobiotecnologia 2008, and CNPq (National Council of Technological and Scientific Development). The authors also wish to acknowledge the funding support received from the High Education Authority's Programme for Research in Third-Level Institutions Cycle 5 (Trinity Biomedical Sciences Institute).

\section{Disclosure}

The authors report no conflicts of interest in this work.

\section{References}

1. Carter HB, Coffey DS. The prostate: an increasing medical problem. Prostate. 1990;16:39-48.

2. Barry MJ, Cockett ATK, Holtgrewe HL, McConnell JD, Sihelnik SA, Winfield HN. Relationship of symptoms of prostatism to commonly used physiological and anatomical measures of the severity of benign prostatic hyperplasia. J Urol. 1993;150:351-358.

3. McConnell JD, Roehrborn CG, Bautista OM, et al. The long-term effect of doxazosin, finasteride, and combination therapy on the clinical progression of benign prostatic hyperplasia. N Engl J Med. 2003;349: 2387-2398.

4. Wasson JH, Reda DJ, Bruskewitz RC, Elinson J, Keller AM, Henderson WG. A comparison of transurethral surgery with watchful waiting for moderate symptoms of benign prostatic hyperplasia. $N E n g l$ J Med. 1995;332:75-79.

5. Wilt TJ, Ishani A, Stark G, MacDonald R, Lau J, Mulrow C. Saw palmetto extracts for treatment of benign prostatic hyperplasia - a systematic review. JAMA. 1998;280:1604-1609.

6. Belostotskaia LI, Nikitchenko IuV, Gomon ON, Chaǐka LA, Bondar'VV, Dziuba VN. Effect of biologically active substances of animal and plant origin on prooxidant-antioxidant balance in rats with experimental prostatic hyperplasia. Eksp Klin Farmakol. 2006;69:66-68. Russian.

7. Wadsworth TL, Worstell TR, Greenberg NM, Roselli CE. Effects of dietary saw palmetto on the prostate of transgenic adenocarcinoma of the mouse prostate model (TRAMP). Prostate. 2007;67:661-673.

8. de Souza PA, Palumbo A Jr, Alves LM, et al. Effects of a nanocomposite containing Orbignya speciosa lipophilic extract on benign prostatic hyperplasia. J Ethnopharmacol. 2011;135:135-146.

9. Bercovich E, Saccomanni M. Analysis of the results obtained with a new phytotherapeutic association for LUTS versus control. Urologia. 2010;77:180-186.

10. Markley KS. The babassu oil palm of Brazil. Econ Bot. 1971;25: 267-304.

11. Azevedo A, Ferreira S, Chagas A, Barroqueiro E, Guerra R, Nascimento F. Effect of babassu mesocarp treatment on paw edema and inflammatory mediators liberation. Rev Ciên Saúde. 2003;5:21-28.

12. Pereira da Silva B, Paz Parente J. An anti-inflammatory and immunomodulatory polysaccharide from Orbignya phalerata. Fitoterapia. 2001;72:887-893.

13. Silva CG, Herdeiro RS, Mathias CJ, et al. Evaluation of antioxidant activity of Brazilian plants. Pharmacol Res. 2005;52:229-233.

14. Sakata S, Uchida K, Kaetsu I, Kita Y. Programming control of intelligent drug releases in response to single and binary environmental stimulation signals using sensor and electroresponsive hydrogel. Radiat Phys Chem. 2007;76:733-737.

15. Danhier F, Ansorena E, Silva JM, Coco R, Le Breton A, Préat V. PLGA-based nanoparticles: an overview of biomedical applications. J Control Release. 2012;161:505-522.

16. Barichello JM, Morishita M, Takayama K, Nagai T. Encapsulation of hydrophilic and lipophilic drugs in PLGA nanoparticles by the nanoprecipitation method. Drug Dev Ind Pharm. 1999;25:471-476.

17. Dinarvand R, Sepehri N, Manoochehri S, Rouhani H, Atyabi F. Polylactide-co-glycolide nanoparticles for controlled delivery of anticancer agents. Int J Nanomedicine. 2011;6:877-895. 
18. Ma W, Chen M, Kaushal S, et al. PLGA nanoparticle-mediated delivery of tumor antigenic peptides elicits effective immune responses. Int J Nanomedicine. 2012;7:1475-1487.

19. Li X, Radomski A, Corrigan OI, et al. Platelet compatibility of PLGA, chitosan and PLGA-chitosan nanoparticles. Nanomedicine. 2009;4:735-746.

20. Santander-Ortega MJ, Bastos-González D, Ortega-Vinuesa JL, Alonso MJ. Insulin-loaded PLGA nanoparticles for oral administration: an in vitro physico-chemical characterization. J Biomed Nanotechnol. 2009;5:45-53.

21. Aggarwal S, Yadav S, Gupta S. EGFR targeted PLGA nanoparticles using gemcitabine for treatment of pancreatic cancer. J Biomed Nanotechnol. 2011;7:137-138.

22. Fessi H, Puisieux F, Devissagnet JP, Ammoury N, Betina S. Nanocapsule formation by interfacial polymer deposition following solvent displacement. Int J Pharm. 1989;55:R1-R4.

23. Derakhshandeh K, Erfan M, Dadashzadeh S. Encapsulation of 9-nitrocamptothecin, a novel anticancer drug, in biodegradable nanoparticles: factorial design, characterization and release kinetics. Eur J Pharm Biopharm. 2007;66:34-41.

24. Fonseca C, Simões S, Gaspar R. Paclitaxel-loaded PLGA nanoparticles: preparation, physicochemical characterization and in vitro anti-tumoral activity. J Control Release. 2002;83:273-286.

25. Song X, Zhao Y, Hou S, et al. Dual agents loaded PLGA nanoparticles: systematic study of particle size and drug entrapment efficiency. Eur J Pharm Biopharm. 2008;69:445-453.

26. Murray HH. Traditional and new applications for kaolin, smectite, and palygorskite: a general overview. Appl Clay Sci. 2000;17:207-221.

27. Carretero MI. Clay minerals and their beneficial effects upon human health. A review. Appl Clay Sci. 2002;21:155-163.

28. Dornelas CB, da Silva AM, Dantas CB, et al. Preparation and evaluation of a new nano pharmaceutical excipients and drug delivery system based in polyvinylpyrrolidone and silicate. J Pharm Pharm Sci. 2011;14: 17-35.

29. Presser A, Hüfner A. Trimethylsilyldiazomethane - a mild and efficient reagent for the methylation of carboxylic acids and alcohols in natural products. Monatsh Chem. 2004;135:1015-1022.

30. Jackson F, Longenecker $H$. The fatty acids and glycerides of babassu oil. J Am Oil Chem Soc. 1944;21:73-75.

31. United States Pharmacopeia Convention. US Pharmacopeia and National Formulary. 33rd ed. Rockville, MD: United States Pharmacopeia Convention; 2010.
32. Umerska A, Paluch KJ, Inkielewicz-Stępniak I, et al. Exploring the assembly process and properties of novel crosslinker-free hyaluronatebased polyelectrolyte complex nanocarriers. Int J Pharm. 2012;436: 75-87.

33. Codex Alimentarius. Codex Standard for Named Vegetable Oils. Rome, Italy: Food and Agriculture Organization of the United Nations/World Health Organization; 2001.

34. International Conference on Harmonization. Q2B Validation of Analytical Procedures: Methodology. 1996. Available from: http://www.fda gov/downloads/Drugs/GuidanceComplianceRegulatoryInformation/ Guidances/ucm073384.pdf. Accessed July 7, 2013.

35. Pavlidou S, Papaspyrides CD. A review on polymer-layered silicate nanocomposites. Prog Polym Sci. 2008;33:1119-1198.

36. Giannelis EP. Polymer layered silicate nanocomposites. Adv Mater. 1996;8:29-35.

37. Hasan S, Al Ali H, Al-Qubaisi M, et al. Controlled-release formulation of antihistamine based on cetirizine zinc-layered hydroxide nanocomposites and its effect on histamine release from basophilic leukemia (RBL-2H3) cells. Int J Nanomedicine. 2012;7:3351-3363.

38. Kevadiya B, Joshi G, Patel H, Ingole P, Mody H, Bajaj H. Montmorillonitealginate nanocomposites as a drug delivery system: intercalation and in vitro release of vitamin B1 and vitamin B6. J Biomater Appl. 2010;25:161-177.

39. European Pharmacopoeia. Limiting Residual Solvent Levels in Active Substances, Excipients and Medicinal Products. 5th ed. Strasbourg, France: Council of Europe; 2005.

40. International Conference on Harmonization. Q3C (R4) Impurities: Guideline for Residual Solvents. 2009. Available from: http://www. ich.org/products/guidelines/quality/quality-single/article/impuritiesguideline-for-residual-solvents.html. Accessed July 7, 2013.

41. Fwu CW, Eggers PW, Kaplan SA, Kirkali Z, Lee JY, Kusek JW. Long-term effects of doxazosin, finasteride and combination therapy on quality of life in men with benign prostatic hyperplasia. J Urol. 2013;190:187-193.

42. Ribeiro AF, Rezende R, Cabral LM, Sousa VP. Poly $\varepsilon$-caprolactonenanoparticles loaded with Uncaria tomentosa extract: preparation, characterization, and optimization using the Box Behnken design. Int J Nanomedicine. 2013;8:431-448.

43. Verma NK, Crosbie-Staunton K, Satti A, et al. Magnetic core-shell nanoparticles for drug delivery by nebulization. J Nanobiotechnology. 2013;11:1.
International Journal of Nanomedicine

\section{Publish your work in this journal}

The International Journal of Nanomedicine is an international, peerreviewed journal focusing on the application of nanotechnology in diagnostics, therapeutics, and drug delivery systems throughout the biomedical field. This journal is indexed on PubMed Central,

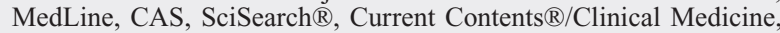

\section{Dovepress}

Journal Citation Reports/Science Edition, EMBase, Scopus and the Elsevier Bibliographic databases. The manuscript management system is completely online and includes a very quick and fair peer-review system, which is all easy to use. Visit http://www.dovepress.com/ testimonials.php to read real quotes from published authors. 